\title{
DEHESAS Y EJIDOS EN LA VILLA Y TIERRA DE MADRID A FINES DEL SIGLO XV
}

\author{
SUMARIO \\ 1. Introducción - 2. La regulación del aprovechamiento económico de aguas \\ y pastos: 2.1. Arroyos - 2.2 Pastos.
}

\section{INTRODUCCIÓN}

El sistema económico existente en Madrid en el siglo XV es de carácter premercantilista ', y se manifiesta en las medidas proteccionistas emanadas del Consejo a través de las ordenanzas y acuerdos adoptados en ayuntamiento. Estas medidas hay que entenderlas en el marco de una economía basada en la explotación del medio natural. La pujante actividad ganadera ha de convivir con la otra tradicional fuente de ingresos madrileña, la agricultura. La Villa, aunque núcleo artesano, rodeada de huertas y campos, ha de considerarse como un centro eminentemente rural en lo que a recursos económicos se refiere. En conseguir este difícil equilibrio entre ambas actividades centra buena parte de sus esfuerzos el Ayuntamiento.

Las medidas del Concejo iban encaminadas a la protección de pastos y abrevaderos de la Villa. Se perseguía que ambos quedaran reservados a los ganados de Madrid, penalizando a los ganaderos de las comarcas y señoríos cercanos que pastaran en ellos y se aprovecharan de las aguas que los recorrían.

\section{LA REGULACIÓN DEL APROVECHAMIENTO ECONÓMICO DE AGUAS Y PASTOS}

\subsection{Arroyos}

El Concejo mostró gran preocupación por los arroyos de la Villa que bañaban los sotos, ejidos y dehesas entre los que discurrían, y se utilizaban para las curtidurías de la Villa y como abrevaderos para el ganado. Prueba de esta inquietud son los hechos que a continuación comentamos.

A pesar de la importancia que la Villa concedía a estos arroyos, algunas tierras que lindaban o eran atravesadas por estas aguas fueron concedidas con derechos de

1 J. LARRAZ LÓPEZ, La época del mercantilismo en Castilla (1500-1700), Madrid, 1943, pp. 21 y ss. y M.A. LADERO QUESADA, España en 1492, «Historia de América Latina. Hechos. Documentos. Polémica», Madrid. 1978, p. 82. 
propiedad a determinadas personas, e incluso se dieron privilegios para la utilización del agua por particulares. En la segunda mitad del siglo XV, esta práctica obligó al Concejo a establecer, el día nueve de abril de 1484, la inalienabilidad de los álveos, no pudiéndose vender ni permutar ni dar a censo sobre ellos a ninguna institución ni particular ${ }^{2}$. Asimismo, se estableció que no se podía utilizar ningún tipo de construcción en los cauces sin licencia del Concejo, reservándose éste la potestad de derribarla si perjudicaba en alguna manera a la comunidad madrileña ${ }^{3}$.

Sin embargo, los regidores continuaron dando a censo tierras situadas en las proximidades de las riberas. Este fue el caso del arroyo de Abroñigal, donde la concesión de tierras a censo llegó a tal punto que en 1485 el bachiller Yanguas tuvo que declarar en sentencia que Madrid era propietaria del arroyo, su agua y abrevadero ${ }^{4}$.

Como se ve, la política concejil era la de proteger estos abrevaderos naturales y que su utilización no se limitara a unos pocos. También le preocupó los daños que estas aguas de arroyada podían causar sobre los ejidos y dehesas por donde discurrían y de los que obtenían importantes beneficios mediante su arrendamiento. En las orillas de los ríos Jarama y Henares solían construir canales cuyo uso se destinaba a la agricultura y a la pesca '. La construcción indiscriminada de éstos empezó a resultar dañina para los ejidos; por ello se decidió el tres de agosto de 1470 prohibir su construcción en las orillas de los ejidos, imponiéndose penas de tres mil maravedis y la pérdida de los materiales empleados en la construcción, que sería demolida ${ }^{6}$. Los motivos del Concejo para tomar tales medidas eran los de mantener íntegras las orillas de los ejidos y dehesas que, situadas en las riberas de los ríos madrileños, iban reduciéndose con el paso de los años debido a la acción erosiva de sus aguas, sobre todo en la época de fuertes avenidas, que en más de una ocasión asolaron la región. Debido a esta erosión el cauce de los ríos aumentaba con el tiempo en detrimento de las dehesas y ejidos a los que iba ganando terreno. Esta acción erosiva impedía que a esas riberas se acercara el ganado a beber y, así pues, hacía inviable el uso de ellos como abrevaderos. Para remediar esta situación el Concejo procedió a la construcción de estacadas y jurdías ciegas para retener las arenas e impedir que fuesen arrastradas por las aguas. Esto es lo que se hizo en el Porcal, ejido situado en la orilla derecha del río Jarama. La reparación de esta orilla era muy necesaria pues se utilizaba como embarcadero del ganado que se llevaba a pastar en dicho ejido. Los

2 A. Millares Carlo, Índice y extractos de los Libros de Cédulas, "Contribuciones Documentales a la Historia de Madrid», Madrid, 1971, p. 151.

3 Libros de Acuerdos del Concejo Madriletio, I (1464-1485), ed. de A. MillareS CaRLo y G. ARTILES RODRíGUEZ, Madrid, 1932, p. 318.

4 Archivo de Villa, Secretaria, 3-37-91. Otro ejemplo significativo de la política concejil es el de Alonso Arias Dávila, quien obtuvo una heredad surcada por el arroyo Butarque, en término de Leganés; surgieron problemas por su aprovechamiento con el citado Concejo, que le acusaba de haber desviado el cauce del río hacia sus tierras, privando de agua al ganado del municipio. Las protestas de ambos se presentaron en la Villa y ésta confirmó su licencia a Alfonso Arias Dávila, pues se comprobó que la desviación del cauce del río efectuada por aquél resultaba mucho más beneficiosa a Leganés, ya que el nuevo cauce pasaba por tierras comarcales a las que todos los vecinos podían acudir libremente con los ganados. Archivo de Villa, Secretaría, 3-36-32.

3 A. TORREBLANCA LÓPEZ, El aprovechamiento del agua en Madrid, trabajo inédito, hoja 71.

6 Archivo de Villa, Secretaria, 3-36-17 y Libros..., I, p. 201. 
desperfectos ocasionados la habían hecho inutilizable, y la barca destinada a este uso había dejado de usarse'.

\subsection{Pastos}

No todas las zonas de pasto eran propiedad concejil. Algunos prados y dehesas, los menos, eran comunales, es decir, de todos los vecinos de la Villa, quienes podían usarlas libremente; otros se consideraron como bienes de propios y por tanto de explotación regulada por el Concejo, mediante el pago que éste estipulara y con las limitaciones por él impuestas; finalmente, otros eran de particulares, muchos de los cuales los tenían en arriendo. Del arrendamiento de estas dehesas y ejidos el Concejo obtenía grandes beneficios y ante la necesidad de ingresos tendió a aumentar el número de los explotados como propios en detrimento de los pastos comunales -ejemplo la dehesa de Arganzuela-; si a esto añadimos que algunas dehesas estaban destinadas a un uso determinado -la dehesa de Amaniel para el ganado de las carnicerías de la Villa-, llegamos a la conclusión de que la mayoría de los vecinos de Madrid, que tenían que mantener a sus animales de labor, se veían obligados a pagar por el derecho de pasto. Por este motivo y dada la facilidad con la que el ganado, al trasladarse de un lugar a otro, podía entrar en los terrenos vedados, las intromisiones en zonas privadas se repetían sin cesar ${ }^{8}$. Se quejaban los propietarios y los renteros del Concejo o de particulares de que los campos eran talados y destruidos por personas ajenas que entraban a cortar leña, pescar, cazar o aprovecharse de sus pastos. Ello iba en detrimento de su propia utilidad y, además, debido a la baja productividad que los terrenos tenían por los daños causados, no encontraban quién quisiera hacerse cargo de su arriendo. Lo mismo ocurría con los de propiedad concejil: se cazaba, cortaba leña o pastaba sin compensación monetaria en perjuicio del arrendador que perdía en el negocio. El Concejo se vió obligado a dictar una serie de ordenanzas que pusieran fin a tales desmanes ${ }^{9}$. Se prohibió la entrada a cualquier hato de ganado en prados, dehesas o sotos de la Villa y su tierra. De todo ganado que fuera hallado dentro de un campo, el dueño de éste, su mayordomo, criado o rentero, y si fuese propiedad de la villa cualquier vecino estaba en su derecho de tomar para sí dos cabezas de ganado no semental si el hecho tenía lugar de día y cuatro de noche. Si no se encontrase el ganado dentro pero se supiera por pesquisa, el dueño del ganado debería pagar en moneda en función del número de cabezas de ganado y del tamaño

\footnotetext{
7 Archivo de Villa, Secretaria, 3-169-12 y Libros de Acwerdos del Concejo Madriletio, II (1486-1492), ed. de A. GÓMEZ IGLESIAS, Madrid, 1970, p. 154.

8 Los límites entre propiedades privadas generalmente se señalaban mediante mojones de piedra espaciados entre si. Uno de los factores principales de delimitación eran los accidentes naturales -arroyos, montes y colinas, valles, etc...- 0 artificiales -caminos, senderos, zanjas, etc...- La delimitación, por si sola, no constituía un obstáculo al ganado que podía pasar libremente de una propiedad a otra. El respeto del pasto ajeno se debía más a un pacto consuetudinario entre las partes, ya de palabra o por escrito.

9 Me refiero a las Ordenanzas de Policía Rural publicadas por Timoteo DOMINGo PALACIO en Documentos del Arcbivo General de la Villa de Madrid, (1444-1500), Madrid, 1906, pp. 515-548; y a las «Ordenanzas de los ganaderos de la Villa y su tierran, fechadas hacia 1495 y todavía inéditas, Archivo de Villa, Secretaría, 2-309-26. Aunque estas ordenanzas legislaban todo el aprovechamiento relativo a dehesas y ejidos, en las páginas que siguen sólo me referiré a ellas por lo que respecta al aprovechamiento ganadero.
} 
de éste, como se explicó más arriba ${ }^{10}$. Se estipulaba la misma pena para quien entrase en la dehesa de Amaniel y la de Arganzuela ". También se legisló sobre la siega de hierba en las zonas reservadas para pasto imponiendo penas elevadas, además de la pérdida de la hierba cortada ${ }^{12}$.

Como se viene observando, las pretensiones del Concejo y particulares eran la obtención de ingresos económicos a cambio de la utilización de sus tierras: sotos, ejidos, dehesas. De ahí la penalización a los que entrasen sin el derecho concertado previo pago o acuerdo. Muchos vecinos que no querían pagar o no podían hacerlo incumplían las leyes dejando que su ganado paciese libremente tanto en los pastos vedados como en las tierras cultivadas aludiendo que no habían podido evitarlo. El Concejo se vió obligado a establecer una rígida legislación al respecto ${ }^{13}$.

\subsubsection{Ejidos}

Esta denominación abarca todo terreno contiguo a un pueblo, generalmente a urillas de ríos o arroyos ${ }^{14}$, aptos para el pasto de los ganados de los vecinos, pues en ellos estaba prohibido labrar y guardaban un grado de humedad aceptable para mantener fresca la hierba. La importancia que para la Villa tenían se refleja en el elevado precio que alcanzaban en las pujas de arrendamiento ${ }^{15}$, ya que como bienes de propios del Concejo éste los daba a particulares, que a cambio de un dinero gozaban del derecho a la utilización de estos términos. Sin duda, al igual que las dehesas, como luego se verá, también había ejidos propiedad de los concejos de la tierra madrileña y cuyo aprovechamiento no era regulado por la Villa, esto es, no eran considerados bienes de propios y por tanto su explotación la ejercían los vecinos del Concejo del que eran propiedad.

Se tienen datos de la existencia de unas ordenanzas que regulaban el uso de los ejidos, fechadas hacia $1380^{16}$; aunque no han llegado hasta nosotros, se ha podido conocer por datos aislados algo de su contenido. Así, se sabe que prohibían la siega de hierba so pena de cinco maravedís, pues debía ser guardado para el alimento de potros y bueyes. Más de cien años después, en ventiseis de abril de 1497, se obtuvieron mil ochocientos maravedís, de pena por haber arrendado la hierba de "Sotil de Lobos» a un vecino de Arganda ${ }^{17}$. Esto pone de manifiesto la importancia

10 Documentos del Archivo de Villa, III, pp. 514-18.

11 Documentos del Archivo de Villa, III, p. 547.

12 Documentos del Archivo de Villa, III, p. 528.

13 Documentos del Archivo de Villa, III, pp. 516-18, 519- 20 y 529. Archivo de Villa, Secretaría, 2-422-12 y Libros de Arwendos del Concejo Madrileño, IV (1498-1501), ed. de C. RUBIO PARDOS, R. SÁNCHEZ GONZÁLEZ y C. CAYETANO MARTÍN, Madrid, 1982, pp. 39-41.

14 Acuerdo del treinta de septiembre de 1464: «Los ejidos que son del concejo de esta Villa así en las riberas del Jarama como de Guadarrama.... (nombre que recibía entonces el río Manzanares). Libros..., I, p. 7.

is Los precios del arrendamiento de los ejidos subieron progresivamente desde 1448 -en que se fijó una cifra de cuatro mil maravedís- a 1501 -año en que se alcanzaron los treinta y cinco mil-; siendo en 1519 de cuarenta y ocho mil maravedís. L. MARTíNEZ, Las bienes de propios en la villa de Madrid (Memoria de Licenciatura inédita), Madrid, 1986, hoja 164.

16 Sobre la desaparición de estas ordenanzas y su recomposición a través de datos sueltos, véase: $L$. MARTínEZ, Los bienes de propios..., hoja 153.

17 Libros de Acuerdos del Concejo Madrilento, III (1493- 1498), ed. C. RUBIO PARDOS, T. MORENO VAlCÁRCel, C. DE lA FUeNTE COBOS y E. MENESES GARCí M, Madrid, 1979, p. 307. 
que se concedía a los ejidos como zonas de pasto para animales de labranza y carga. Ocurría con las dehesas algo parecido: salvo excepciones, se consideraban terreno vedado a todo tipo de ganado menos el de labranza y arreo. La razón es fácil. En época medieval había pocas personas que contasen con un número grande de animales: vacas, ovejas, cabras, caballos, etc.; lo más frecuente era encontrar simples campesinos propietarios de un buey, que compartían con el vecino para las faenas del campo, y algún asno o animal de arreo, amén de una vaca o cabra de la que obtenían leche y queso. Los grandes ganaderos, que se dedicaban al negocio de la cría de ganado, contaban generalmente con pastos de su propiedad con los que alimentar éste; de ahí que la Villa velase por la salvaguarda de esas hierbas reservándolas a los vecinos, quienes de este modo podían alimentar sus animales, compañeros de las tareas agrícolas.

Hacer una enumeración completa de todos los ejidos de la Villa y su alfoz es casi imposible. Sin embargo, rastreando en las fuentes se puede confeccionar una lista. En los Libros de Acuerdos del Concejo se entresacan los siguientes: Ribas, El Negralejo, Sotil de Lobos, Berrueco, Humanejos - ¿Humanes de Madrid?- Villaverde y Aluche ${ }^{18}$. En las sentencias del pesquisidor Alonso Díaz de Montalvo se citan una serie de términos usurpados a ejidos, entre ellos El Porcal, además de los ya citados Ribas y El Negralejo.

El arrendamiento de los ejidos se efectuaba por un periodo de tiempo de seis años. La paga y remate se realizaba el día de San Marcos -diciembre- y se estipulaban dos pagas anuales, una en Navidad y otra en Carnestolendas ${ }^{19}$. El arrendamiento llevaba anejos una serie de derechos y obligaciones. El arrendador disfrutaba del derecho de caza, pasto, pesca y recogida de leña; podía conceder licencia a ciertas personas, a quienes mediante iguala con los arrendadores se les permitía hacer uso de los recursos económicos que ofrecía el ejido; asimismo, podían efectuar un número determinado de estacadas, para favorecer la pesca. Desde 1464 obtuvieron el derecho de cobrar las penas impuestas a los que sacaran leña así como a los que construyeran corrales o parideros con la misma.

En contrapartida, tenían una serie de obligaciones como eran las de vigilar los daños que pudieran ocasionar los animales al pacer, construir jurdías ciegas y pescaderas ${ }^{20}$, evitar la caza mediante artes prohibidas y la saca de leña indiscrimina$\mathrm{da}^{21}$.

18 Libros..., I, p. 201 (1482-X-9); Libros..., I, p. 120 (1481-VIII-13); Libros..., III, p. 205 (1497-IV-26); Libros..., I, p. 35 (1479-V-4) y Libros..., III, p. 188 (1495-XI-4), respectivamente.

19 L. MARTíneZ, Los bienes de propios... hoja 163.

20 A. MillaRES CARLO, Índice y extractos del Libro Horadado, „Contribuciones documentales a la historia de Madrid», Madrid, 1971, p. 26.

21 Libros..., I. p. 125. Véase también L. MARTínEZ, Los bienes de propios..., hojas 156-58.

22 En la mayoría de los casos no ha quedado constancia de estas cláusulas pero si hay recogido en los Libros de Acuerdos algún caso curioso. Se documenta el hecho de una puja efectuada por Juan de Tapia, que parecía dar entrada en ella a caballeros y escuderos. Otro pujador manifestó su desacuerdo con las condiciones establecidas por el anterior, ya que según aquél en las cláusulas no se excluía a los regidores quienes tenían prohibido por ley participar en arriendos de cualquier tipo. Se desconoce si, tras el aparente error, en las condiciones de Juan de Tapia se escondía una clara muestra de favorecer a los regidores de la Villa, de cuya corruptela ya se ha hablado. Otra puja con cláusulas específicas fue también la de Benito Romano, quien solicitó se le permitiera hacer una presa y sacar del ejido la leña que necesitase. El concejo no aceptó por ser en contra de las ordenanzas. V. Libros..., I, Pp. 170, 171 y 172. 
Los arrendadores junto con el precio ofrecido imponían, a veces, una serie de condiciones que el Concejo podía aceptar o no ${ }^{22}$.

\subsubsection{Debesas}

Las dehesas y los prados de Madrid eran utilizados para alimento de las bestias de labranza, silla y carga, estando prohibido que pacieran los ganados ovejunos y porcinos ${ }^{23}$. Se define la dehesa como un campo acotado generalmente de prados y destinado a pastos. Pero no se dedicaba sólo a ello; las dehesas eran por su disponibilidad de agua terrenos aptos para el cultivo, por lo que con frecuencia se utilizaban indebidamente por los vecinos de la Villa ${ }^{24}$. Así pues, la demanda de dehesas por parte de los vecinos hay que entenderla no sólo por el uso pecuario que podían darles, sino también por el aprovechamiento agrícola. En ventisiete de mayo de 1489 los Reyes Católicos dieron una provisión por la que se prohibía a los lugares comarcanos hacer dehesas nuevas en perjuicio de los vecinos de la Villa ${ }^{25}$. Sin embargo, en la última década del siglo XV, los concejos de la tierra de Madrid parecen haberse puesto de acuerdo para solicitar a la Villa la concesión de dehesa nueva o la ampliación de la ya existente: Leganés y Villanueva en 1492, San Sebastián de los Reyes en 1493, Fuencarral en 1494, Valaño en 1495, un año después Carabanchel y «Humanejos», Chamartín y «Polvorança» en 1497, Alcorcón y las Rozas en $1500{ }^{26}$. Los motivos alegados por estas aldeas de la tierra de Madrid son entre otros los siguientes:

a. interés porque el lugar se poblase (Chamartín) manejos").

b. el aumento demográfico que exigía más tierra de pasto y de cultivo ( «Hu-

c. la despoblación que la falta de tierras de pasto estaba ocasionando en el lugar (Leganés).

d. las dehesas viejas se habían vuelto estériles y eran necesarias nuevas tierras (Fuencarral).

e. la falta de terrenos adecuados para el alimento del ganado conllevaba la entrada de éste en zonas vedadas con el consiguiente pago de penas y caloñas que suponía la ruina de muchas familias (Carabanchel) ${ }^{27}$.

Pero detrás de estas argumentaciones se escondían motivos de mayor peso. Ya se habló en otro apartado de la propiedad eminente de las dehesas; se dijo entonces que

23 Ordenanzas de prados y dehesas (1496-X-12) en Libros..., III, p. 161.

24 Acuerdo de veintisiete de noviembre de 1489: «Mandaron que porque diz que ay çierta rotura nueva, fecha en la dehesa de Valaño, e esta sembrado, que se coma con ganado...n. Libros..., II, p. 191. Caso significativo es el del Comendador Robredo, propietario de unas casas cercanas a la dehesa de Amaniel, que deliberadamente se apropió de terrenos de la dehesa colindantes con sus propiedades, para sembrar en ellos. Archivo de Villa, Secretaría, 3-127-2 (1475-IV-6); véase el apéndice documental 1.

2s Archivo de Villa, Secretaría, 2-158-45 (1489-V-27), véase el apéndice documental 2.

26 Libras..., II, p. 315 (Leganés); Libros..., II, p. 359 (Villanueva); Libros..., III, p. 3 (San Sebastián de los Reyes); Libros..., III, p. 69 (Fuencarral); Libros..., III, p. 271 (Carabanchel); Libros..., III, p. 128 (Valaño); Libros..., III, p. 243 (Humanejos); Libros..., III, 303 (Chamartín); Libros..., III, p. 280 («Polvorança»); Libros..., IV, p. 194 (Alcorcón).

27 Libros..., III, p. 303 (a); Libros..., III, p. 243 (b); Libras..., II, p. 315 (c); Libros..., III, p. 70 (d); Documentos del Arcbivo de Villa, III, p. 483 (e). 
algunos concejos del alfoz gozaban de dehesas propias para su exclusivo aprovechamiento. A éstas no tenían acceso los vecinos de la Villa, sólo los del lugar quienes por esta razón disfrutaban de pastos más abundantes. Pero el verdadero interés era económico: poseer en propiedad una dehesa "dehesada", esto es, vedada al libre acceso de todo tipo de ganados, suponía para ese Concejo el disfrute de las penas y caloñas que se percibían por meter ganado indebidamente en las dehesas y contravenir otros artículos de las ordenanzas. Por su parte, la Villa, que gozaba de una posición de fuerza con respecto a los lugares de su tierra, se aseguraba que la concesión de estos terrenos solicitados no iba en detrimento de los intereses de sus vecinos, por lo que no otorgaba las dehesas pedidas sino en lugares propiedad del Concejo que solicitaba la concesión, como es el caso de Fuenlabrada, a quien se le otorgó porque «... dexan para la Villa y pasto común della la que antes tenían" ${ }^{28}$; o en lugares no perjudiciales tales como baldíos, que sin embargo tuvieran buena disposición para el pasto por ser zonas de valle, tomillares, juncos, etc... ${ }^{29}$.

Esta demanda de dehesas generalizada en el alfoz madrileño, en la última década del siglo XV, tenía que estar motivada por algún acontecimiento histórico o demográfico que estuviera ocurriendo o gestándose por aquellos años. Se pueden exponer al menos tres argumentos que expliquen el por qué de esta demanda generalizada:

- En primer lugar el aumento de población experimentado en la segunda mitad del siglo XV, tras salir de la crisis demográfica causada por las pestes y catástrofes del siglo XIV ${ }^{30}$. Este aumento poblacional provocó un incremento de la demanda de alimentos que, a su vez, exigía más y mejores tierras de cultivo. En las dehesas se podían dedicar unas cuantas fanegas a la siega y, más aún, eran de absoluta necesidad para los animales de labranza y arreo, tan necesarios para el hombre en las faenas del campo.

- Otra explicación sería el intento de los concejos de la tierra de Madrid de iniciar su independencia fiscal respecto de la Villa, ya que, como es sabido, las aldeas dependían fiscal, administrativa y jurisdiccionalmente de aquélla $\left.{ }^{31}\right)$. Independencia que no se alcalzó hasta siglos después.

- Una tercera interpretación, la que menos me satisface, se basaría en la analogía; según ésta, por imitación de otros, los concejos de la tierra de Madrid irían solicitando a ésta la dehesa "dehesada», para sentirse en igualdad de condiciones ${ }^{32}$.

28 Libras..., III. p. 66.

29 Documentos dol Arcbivo de Villa, III, p. 483.

30 M. MONTERO VAlLEjO, El Madrid modieval, Madrid, 1987, p. 245; se refiere a esta recuperación madrileña en aquellas fechas.

${ }_{31}$ R. GIBERT y SANCHEZ DE LA VEGA, El concojo de Madrid. Sw organización on los siglas XII-XV, Madrid, 1949, p. 85.

32 Leganés pidió que «porque todos los lugares tienen dehesa y Leganés no que se la manden señalarw. Incluso mandaron suplicación a los Reyes para que la Villa diera dehesa a los lugares que no la tenían, Libras..., III, p. 152; «... segund que se llevan de las otras dehesas de los otros lugares de la tierra de Madrid» («Humanejos»), Libros.... III, p. 243; *... regund que las otras deheses dehesadas de los otros lugares de la tierra desta Villa.... (Alcorcón), Libros..., IV, p. 194; lo mismo San Sebastírn, Libros..., III, p. 3; «...como gozan los otros lugares de tierra de los que tienen» («Polvorança»), Libros..., III, p. 280. 
A todos los concejos mencionados anteriormente se les otorgó la dehesa, pero había otros lugares del alfoz de los que, aun no habiendo quedado constancia de su petición, sabemos que la poseían por aquellas fechas. Tal es el caso de las dehesas de Fuenlabrada, Alameda, Alexander y el Porcal ${ }^{33}$. A continuación se analizan la situación y características de algunas dehesas.

Valaño

Situada entre San Sebastián de los Reyes y Villanueva, aparece por primera vez en la documentación en veinticuatro de noviembre de 1489 , a raíz de una sentencia pronunciada por el bachiller Diego Arias de Anaya ${ }^{34}$. Ese mismo año, un mes después, se pregona su arrendamiento. Debía encontrarse Villanueva despoblada y el arrendamiento de la dehesa podía ayudar a repoblarla, ya que en virtud de una donación hecha por Madrid, Villanueva poseía la mitad de la dehesa de Valaño ". Dos años después se arrendó con la obligación, por parte del adjudicatario, de avecindarse allí sin poder cambiar de lugar para no perder el arrendamiento y vigilar la dehesa de los daños que se pudieran ocasionar; se valoró en tres mil maravedís anuales ${ }^{36}$.

\section{Carabanchel}

En 1497, el alcalde de Carabanchel de Abajo presentó una petición a la Villa solicitando una dehesa porque no tenían donde apacentar sus ganados los más de cuarenta vecinos que allí vivían. Según se desprende del texto de las Actas de los Libros de Acuerdos, ambos Carabancheles, el de arriba y el de abajo, compartían en aquella fecha dehesa. El problema se presentó por el aumento de población en ambos lugares fundamentalmente en Carabanchel de Arriba que, propietario de la dehesa, impedía que los de Carabanchel de Abajo llevaran a pastar sus ganados argumentando y probando con documentos que la dehesa les había sido donada a ellos ${ }^{37}$. La Villa, como más arriba quedó explicado, reacia a la concesión de una nueva dehesa, no hizo caso del problema ${ }^{38}$. Ante esta actitud, Carabanchel de Abajo se dirigió a los Reyes Católicos y éstos dieron una cédula mandando a la Villa les asignasen dehesa. Los pesquisidores verificaron la realidad de lo expuesto por Carabanchel de Abajo. Estos vecinos no tenían dehesa propia, salvo un prado pequeño destinado a eras; por otro lado, Carabanchel de Arriba tenía una población de más de cien vecinos, lo que hacía inviable el uso por ambos lugares de una dehesa común ${ }^{39}$.

. 33 A. Millares Carlo, Indice y extractos de los Libros de Códulas, p. 128; Alameda y Alexander, se cree de propiedad particular, Archivo General de Sim8ancas, Registro General del Sello, abril-1494, fol. 540 y Libros..., II, p. 141.

34 Libros..., II, p. 189.

35 Libros..., III, Pp. 300-301.

36 L. MARTINEZ, Los biomes de propios..., hoja 268.

37 Libros..., III, p. 283.

38 Libros..., III, p. 271.

39 Se vio, ademis, un beneficio para la Villa en la concesión de la dehesa; Docmmontos dal Arcbivo de Villa, III, p. 483. 
Amaniel

El nombre de esta dehesa propiedad de la Villa proviene del arroyo donde se forma. Durante la Edad Media, conoció otras denominaciones como la de San Bernardino, tras la fundación en el lugar de un convento bajo dicha advocación; o dehesa de la Villa, nombre con el que llegó a nuestros días ${ }^{40}$.

En 1434 se restablecieron sus términos, siendo un monte concejil que lindaba con el de Cantarranas, próximo a los arroyos Beacos y Zarzuela ${ }^{41}$.

Amaniel había sido en principio pasto común ${ }^{42}$, luego fue dado en exclusividad para los ganados de los obligados a las carnicerías. Desde ese momento se mandó sacar todos los animales que hubiese en la dehesa bajo pena de perderlos tomados por cualquier vecino ${ }^{43}$. El aumento demográfico antes aludido llevó años más tarde, en 1530, a la concesión por el monarca del permiso para arrendar treinta fanegas en la dehesa. Ello provocó malestar y protestas, por eso se decidió que una vez recogida la cosecha la dehesa volviera a dedicarse al pastizaje ${ }^{4}$.

Cerca de la dehesa el Comendador Alonso Robredo poseía unas casas donde encerraba su ganado; éste al salir a pastar causaba daños en el término de la dehesa, por lo que solicitó en repetidas ocasiones a la Villa le concedieran una zona de salida para su ganado. En 1457, le fue señalado un lugar donde podían entrar y salir los animales "s. Aprovechándose de este terreno que la Villa le había estipulado para entrada y salida del ganado, el Comendador se adueñó de parte de la dehesa en su propio beneficio. Esto obligó a una serie de inspecciones por parte de la Villa para restablecer los verdaderos límites de la dehesa, pues Alonso Robredo había levantado unas tapias más allá de sus lindes, hecho que se supo por indagaciones entre los habitantes del lugar. Éstos afirmaron que el Comendador disfrutaba de aquellas tierras desde hacía mucho más de diez años, en las que sembraba y había plantado algunos majuelos. Por estos mismos vecinos se supo que en más de una ocasión los regidores habían mandado comer con el ganado la tierra cultivada por el Comendador ${ }^{46}$.

Arganzuela

La dehesa de Arganzuela, situada a orillas del Manzanares, fue construida por el Concejo en los últimos años del siglo XV, tras reunir un cierto número de tierras y viñas adquiridas por la Villa mediante trueques y compras. Parece que la vega, más tarde convertida en dehesa, fue propiedad de un matrimonio que poseía además un soto y un molino. En 1427 , se presentó el problema de su aprovechamiento y, enviados los licenciados Marcos y Guadalajara para poner

40 A. GOMEZ IGLESIAS, Debesa de Amaniel o de la Villa, «Anales del Instituto de Estudios Madrileñosn, II (1967), pp. 34- 35.

41 IDEM, lbidem, pp. 38-39.

42 Archivo de Villa, Secretaría, 3-127-2, véase el apéndice documental 1.

43 Libros..., I, p. 379.

44 Archivo de Villa, Secretaría, 3-127-3 y 3-127-6.

4s Archivo de Villa, Secretaría, 3-127-2, véase el apéndice documental 1.

46 Idem. 
fin al litigio, reconocieron al matrimonio su propiedad pero restituyeron a Madrid la posesión de la isla de Arganzuela, cercana a los citados soto y molino, que siempre había sido de aprovechamiento comunal ${ }^{4}$.

El dos de marzo de 1492, la Villa solicitó licencia a los Reyes para comenzar los trueques y compras necesarios a fin de «... hacer una dehesa... porqués mucha utilidad y provecho a la dicha Villa.... Unos meses más tarde los monarcas concedieron la licencia solicitada ${ }^{4}$. A partir de ese momento y hasta fines de 1497 la Villa negoció con los propietarios de las tierras del «circuito» fijado por el Concejo para dehesa. Los Libros de Acuerdos registran algunas de las resoluciones adoptadas entre la Villa y los vecinos que tenían que vender o cambiar sus propiedades. El grueso mayor de las tierras debió de pertenecer a los descendientes del matrimonio del que antes se habló, a tenor de los repetidos acuerdos entre los regidores y personas nombradas por los uherederos de Arganzuelaw, para xatar con aquéllos ${ }^{\circ}$. Además de éstos, muchos otros se vieron afectados por la constitución de la dehesa ", entre ellos el licenciado Rodrigo de Coalla, Contador Mayor de Cuentas, que nombró a una persona para que con otra, elegida por el Concejo, tasasen juntos unas tierras de su propiedad para la creación de la dehesa ${ }^{32}$. Parte de los terrenos se tasaron y a cambio se entregaron otros de valor similar ". Pero otra porción considerable hubo que comprarla. No se puede saber con exactitud el coste total. Para hacer frente a la adquisición de los terrenos el Concejo recurrió, la mayoría de las veces, a sisas o repartimientos ".

Además, hubo de enfrentarse a las quejas de los vecinos que no estaban conformes con la tasación efectuada y reclamaban más dinero ". La nueva valoración supuso un incremento de 15.000 maravedís, que se obtuvieron a través de una nueva sisa repartida a partes iguales entre la pescadería de los caballeros y escuderos y la de los pecheros ${ }^{\text {*6 }}$.

Otro problema fueron los barbechos situados en la zona destinada a la dehesa: el Concejo prohibió que se sembraran so pena de perder la cosecha ". Asimismo, se ordenó a Juan de Murcia y a Francisco de Daganzo que tasaran el valor de los barbechos para pagarlos a sus dueños ${ }^{\text {s }}$.

47 A. GÓMEZ IGLESIAS, El Madrid medieval, Madrid, 1966, pp. 22-23.

4. Libros..., II, Pp. 328-29.

49 Provisión de los Reyes Católicos, fechada en 15 de mayo de 1492, Archivo de Villa, Secretaría, 3-90-12 y Documentos del Arcbivo de Villa, III, pp. 341-46.

so Acuerdo del 24 de enero de 1494, Libros..., III, p. 64; acuerdo fechado en 10 de febrero de 1494, Libros.... III, p. 67 y acuerdo de 31 de julio de 1495, Libros..., III, p. 167.

s1 1491, junio, 20. Medina del Campo. Licencia a la Villa de Madrid para imponer en ella y sus arrabales una sisa de 130.000 mrs. que necesita para indemnizar a ciertos vecinos cuyos campos han de ser aprovechados para dehesa común en ella. Consejo. Archivo General de Simancas, Registro General del Sello, junio-1494, fol. 14.

52 Archivo General de Simancas, Registro General del Sello, enero-1496, fol. 112.

33 Libros.... II, Pp. 328-29.

I4 AGS, RGS, junio-1494, fol. 14. Archivo de Villa, Secretaría, 3-297-6. A. MILLARES CARLO, Concribuciones, p. 113. Libros..., Pp. 143 y 167. Según A. MONTURIOL el gasto se concentró este año con una cifra de 120.000 mrs., Estructura y evolución dol gasto en la Hacienda Municipal de Madrid: último toncio del siglo XV, «En la España Medieval», IV (1984), p. 683.

ss Libras.... III, pp. 182-83.

s6 Acuerdo fechado en cinco de marzo de 1496, Libras..., III, p. 215.

37 Libros..., III, p. 181.

\$8 Libros.... III, Pp. 186 y 190. 
El veintidós de diciembre de 1497 la dehesa estaba lista para su arriendo y así se hizo saber por medio de un pregón público. Diego Merchán y Alonso Martínez pujaron 5.000 maravedís. Inmediatamente surgieron las protestas de los vecinos y cinco días más tarde tuvo que acordar el Concejo «... que no se arriende porque non vienen conforme todo el pueblo con ella..." ". Se sabe que a partir de 1500 la dehesa fue arrendada y en precios muy elevados ${ }^{60}$. La oposición de los vecinos al arriendo de la dehesa se basó en la contravención de las ordenanzas que regulaban la utilización de la redonda. Con anterioridad al intento de arriendo a particulares para su explotación, la dehesa fue destinada exclusivamente para pasto de las bestias de labor y arreo. El conflicto se provocó al arrendarla para alimento de ganado ovejuno, según se desprende del acta concejil donde se acordó el arriendo ${ }^{61}$. La decisión del Concejo de arrendar la dehesa para ganado ovejuno, además de contravenir una norma concejil, favorecía a la oligarquía madrileña, poseedora de rebaños, en detrimento de la generalidad de los vecinos de Madrid. La presión popular dejó el acuerdo sin efecto, gracias al respaldo que los habitantes de la Villa tenían en la institución del corregimiento. Postura que se encuadra dentro de la política general de los Reyes Católicos de controlar la vida de los concejos favoreciendo a sus pobladores frente a las oligarquías urbanas. En esto redunda la propia ordenanza antes mencionada ${ }^{62}$. Las normas aquí recogidas prohibían la entrada en la dehesa a todo tipo de ganado a excepción de caballos, potros, mulas y asnos, previa licencia del Concejo por ser dehesa «dehesada». En otro apartado de la ordenanza, se prohibía juntar estas bestias con las yeguas; la explicación del hecho es bien sencilla: las yeguas se apartaban porque, al ser consideradas animales para la cría, el propietario de las mismas las reservaba para el semental por él elegido para el cruce. Se imposibilitaba así que las yeguas paciesen junto con el resto de los animales para impedir que éstas fuesen montadas por qualquiera de ellos, e incluso estropeadas si lo eran por un mulo, pues perdían la fertilidad.

Por la importancia concedida a las bestias de labor, la ordenanza incluía un apartado dedicado a favorecer la cría de éstas. El Concejo permitía pastar en Arganzuela a potros, muletas y muletos, ya fueran de propiedad de los vecinos de la Villa o de tratantes de ésta, que negociaban con los animales en las ferias. La única condición impuesta consistía, una vez más, en evitar perder los animales con cruces indebidos; de ahí que se prohibiera a toda costa juntar estos animales jóvenes con los adultos.

Contemplaba también la ordenanza el arrendamiento de las penas de la redonda, así como permitía que cualquier vecino pudiera tomar prendas del ganado vedado en la dehesa no estando el arrendador para hacerlo, repartiéndose luego la cantidad entre ambos. Esta situación se había dado en 1496 antes del arriendo de Arganzuela. En esta fecha se denunció ante el Concejo que un hato de ganado

39 Libros..., IV, p. 2.

60 En 1510 un tal Diego la arrendó en 15.000 maravedís, por tres años a 5.000 maravedís cada uno; a este respecto véase lo que dice L. MARTínEZ, Los bienes de propios, pp. 269-70.

61 El arrendamiento se remataría en *quien diere más por ella tanto que no entre en ella otro ganado salvo ovejuno e que no duerma en ella de nochex, Libros..., III, p. 341.

62 Archivo de Villa, Secretaría, 3-68-39, véase el apéndice documental 3. 
ovejuno propiedad de Juan de Córdoba había sido prendido en la dehesa por Juan Ribera. El Corregidor, oídas las partes y consultada la ordenanza, dictó la condena justa ${ }^{63}$.

En 1507 se permitió, desde primeros de año hasta carnestolendas, la entrada en la dehesa a los ganados de los carniceros de la Villa ${ }^{64}$; a partir de este momento fue consideraba dehesa carnicera junto con la Amaniel.

CONCEPCIÓN MENDO CARMONA

Estudio Universitario de Biblioteconomía

y Documentación (Madrid)

63 Libros..., III, p. 350.

64 Archivo de Villa, Secretaría, 3-225-6. 


\section{APÉNDICE DOCUMENTAL}

1475, abril, 6. Madrid.

\section{Diligencias para delimitar la Debesa de Amaniel}

B. Archivo de Villña (A.V.), Secretaría, 3-127-2. Letra cortesana, su estado de conservación es bueno.

En el territorio de Hamaniel, jueves seis días de abril año del nasçimiento de Nuestro Salvador Ihesu Chisto de mill e quatroçientos e setenta e çinco años. Juan Martín, alcalde en la noble e leal villa de Madrid, por ante mi Alonso González, notario e escrivano público en la dicha villa, testigos yuso escriptos, dixo a Martín Sánchez e Bartolomé Sánchez de Hamaniel que presentes estavan, so virtud de juramento de ellos resçebío en devida forma de derecho que le mostrasen por do ivan los mojones antiguos por donde se comiença la dehesa de Hamaniel. E los dichos Martín Sánchez e Bartolomé Sánchez dixeron que començavan los mojones desde enfrente de la sallida de las casas del Comendador que tiene en Hamaniel por una loma la acorda derecha, e fallaron y unos mojones antiguos e andando por la acorda derecha andovieron por la dicha fasta dar a Val de Sarca e al majuelo de Juan Palomino, e fallaron fechas tapias; e el dicho alcalde les preguntó que aquellas tapias se estavan en lo de Madrid e si eran del Comendador, e dixeron que las tapias que estaban en lo de Madrid fechas.

E el dicho alcalde les preguntó si los majuelos que estaban plantados ende de la loma abaxo contra la dehesa de Hamaniel a la mano izquierda quién los avía plantado. Dixeron que aquello que estava plantado que el comendador dizía que lo compró de una biuda, e quel comandador dizía que aquello non estava en la dehesa.

E el dicho Martín Sánchez dixo que desde diez años acá que vido al dicho comendador Alonso de Robredo usar de aquello e lo senbrar pan. E que sabe e vido que los regidores de esta villa // que fallaron çerca la puerta de la casa quel dicho comendador tiene en Hamaniel, como sallen de la casa a mano izquierda, en una tierra junta con la casa, que la tenía senbrada de pan e que mandava comer con los ganados ella; y otra tierra que estaba en frente de ella, senbrada de pan que a ruego del comendador que le dexaron que cogiese el pan, e que dende en adelante que la non senbrara. Fue preguntado que agora que está senbrada la tierra de çerca la casa quién la mandó senbrar. Dixo que lo non sabe porque la ve agora senbrada. Fue preguntado quién mandó fazer unos mojones en la loma de la dehesa de la otra parte del valle próximo de çerca la casa. Dixo que ombres del comendador las fizieron; el dixo que así es como pasó.

E el dicho Bartolomé Sánchez, so virtud del juramento que fizo dixo que ha fasta veinte años que él que mora en la dicha casa de Hamaniel, del dicho comendador, e que sabe e vido que la casa que ende está que dizían regidores de esta villa que estava hedificada en lo del conçejo, e que dizían que la quieren derribar, e que el dicho comendador que dava al conçejo otro troço de tierra como era lo donde estava hedeficada la casa. Fue preguntado por donde iva el comienço de la dehesa. Dixo que por donde él e Martín Sánchez avía señalado, por allí se començava la dehesa. 
1489, mayo, 27. Jaén.

Los Reyes Católicos probiben que se hagan nuevas debesas en el territorio de Madrid, por ser en perjuicio de la Vila.

B. A.V. Secretaría, 2-158-45. Se conserva en una copia fechada en 13 de marzo de 1798.

Don Fernando e Doña Isabel por la gracia de Dios Rey e Reina de Castilla, de León, de Aragón, de Secilia, de Toledo, de Valencia, de Gallicia, de Mallorcas, de Sevilla, de Cerdeña, de Córdova, de Córcega, de Murcia, de Jaén, de los Algarves, de Algesira, de Gibraltar, Conde y Condesa de Barcelona e Señores de Vizcaya e de Molina, Duques de Atenas e de Neopatria, Condes // de Ruisellón e de Cerdania, Marqueses de Oristán e de Gociano a vos, al que es o fuere corregidor de la Villa de Madrid, salud e gracia. Sepades que por parte del concejo, justicia, regidores, cavalleros, escuderos, oficiales e homes buenos de la dicha Villa nos fue fecha relación, por su petición que ante nos el nuestro Consejo fue presentada, diciendo que algunos lugares de señoríos de la dicha Villa comarcanos e con quien la dicha Villa tiene vecindad de pacer e rematar e cercar e amesnar hacen e intentan facer de nuebo ciertas dehesas, no lo podiendo ni debiendo facer de derecho por ser como diz que es en perjuicio de la dicha Villa e de la vesindad que con los dichos logares tiene. E que si algunas veses, vos el dicho corregidor que agora sois o los corregidores pasados habeis querido conocer y esaminar si pueden facer las dichas dehesas diz que los dichos logares que ansi son de señorío se eximen e han eximido de vuestra jurisdicción diciendo que ellos non son sometidos a la jurisdición de esa dicha Villa, e que todavía fasen de nuebo las dichas dehesas en perjuicio de la dicha vesindad; en lo qual diz que si ansi pasase, la dicha Villa e vesinos y moradores de ella rescibirían mucho agravio e daño. E por su parte, nos fue suplicado y pedido por merced (a) sobre ello le proveyésemos de remedio con justicia o como la nuestra merced fuese, e nos tovímislo por bien porque vos mandamos que luego veades lo suso dicho e non // consintades ni dedes logar que los dichos logares comarcanos con quien dicha Villa tiene vesindad fagan nuevamente las dichas dehesas nin alguna de ellas en perjuicio de la dicha Villa e vecinos e moradores de ella, poniéndoles sobre ello las penas que a vos paresciere e bien visto vos fuere, las quales podades executar e executedes en los que rebeldes e inobedientes fueren. Para lo qual, todo que dicho es e para cada una cosa e parte de ello vos damos todo poder complido con sus incidencias e dependencias, anexidades e conexidades, e non fagades ende al.

Dada en la muy noble cibdad de Jaén a veinte y siete dias del mes de mayo, año del Nascimiento de Nuestro Señor Jesucristo de mill e quatrocientos e ochenta y nueve años.

Yo el Rey. Yo la Reina.

Yo Fernand Alvarez de Toledo, secretario del Rey e de la Reina nuestros señores la fice escrebir por su mandado. (rúbrica).

Fernandez Doctor (b).

Día trece del mes de marzo del año de 1798. En el Archivo de Madrid a las once de la mañana (c).

(a) que allade y tacba ms. - (b) En blanco cuatro suscripciones más - (c) En la parte inforior del ms.

[1500], s.m., s.d. Madrid.

Ordenanzas del concejo de Madrid para la dehesa de Arganzuela 


\section{A. A.V., Secretaría, 3-68-39. Letra cortesana, con rasgos de procesal.}

Este dicho día, los dichos señores corregidor e regidores, en el dicho concejo, dixeron que para la guarda e consevaçión de la dehesa, e para que los dichos vezinos de la dicha Villa e moradores de ella e para el pro común de ella, mandaba e mandaron que la dicha dehesa sea dehesada e se guarde por todo el tiempo, e que los ganados vacunos e ovejunos e cabrunos e puercos no entren, para siempre jamás, en la dicha dehesa, so pena de quarenta maravedís de día, e de noche ochenta maravedís, la res vacuna que entrare en la dicha dehesa; e asímismo, que qualquier ganado ovejuno o cabruno que entrare en la dicha dehesa, aya en pena çinco cabeças de día, y de noche dies cabeças de cada hato; e el puerco que entrare en la dicha dehesa de día, aiga en pena de diez maravedís, y de noche doblado.

Otrosí, hordenaron e mandaron en la dicha dehesa no aya de andar ni anden, para siempre jamás, yeguas, ni se pueda dar licencia para que entren en ella las dichas yeguas ni los dichos ganados vacunos, ni yeguas, ni ganado ovejuno ni cabruno, ni puercos, e que las dichas yeguas ayan de pena de día cada cabeça quarenta maravedís, e de noche doblado.

Otrosí, hordenaron e mandaron en el dicho concejo que las otras bestias, así como cavallos e potros e mulas e muletas e acémilas de lazada e bestias asnales que an de paçer la dicha dehesa, no ayan de entrar ni entren en ella a paçer ni la paçan que primeramente sea dada licencia por la justicia, regidores e concejo desta dicha villa quando e por el tiempo que bien visto les fuere, so pena que qualquier bestia o bestias que en ellas fueren tomadas ayan de pena de día, cada cabeça, quarenta maravedís, e de noche doblado.

E asímismo, mandaron e hordenaron que si algún vezino de la dicha Villa o sus arravales toviere fecho o conprare potros o muletas e muletos para tornar o vender, no pueda paçer en la dicha dehesa, salvo con un potro o con una muleta. E las otras personas que quisieren criar para si, que no sean tratantes de potros o muletas, que puedan traer en la dicha dehesa dos potros o muletas.

Otrosí, hordenaron e mandaron que, fasta que otra cosa paresca ser mejor para la guarda e conservaçión de la dicha dehesa, que las penas de suso contenidas de la dicha dehesa se arrienden a la persona o personas que más dieren por ellas. E con la condiçión, que tal arrendador e arrendadores que así arrendaren la dicha dehesa e las penas de ella ayan de hazer e hagan juramento en el dicho concejo sobre una cruz e sobre un libro que estén los Santos Evangelios que guardarán bien e fielmente la dicha dehesa e no dará a ninguna persona que pasça la dicha dehesa, ni lo desimulará e llevará las penas conthenidas en estas dichas hordenanzas, e no las dexarán de llevar por amor ni por ruego ni en otra qualquier manera; e si se hallare que dexa de llevar o executar, lo pague el tal arrendador con las tendidas sentencias; la qual dicha pena sea la terçia parte para el que lo acusare o dixere, e la otra terçia parte para el juez que lo juzgare, e la otra terçia parte para la dicha Villa, e que está dicho e se entienda si por la ventura se hallare que dieren liçencia.

Otrosí, que qualquier vezino desta dicha Villa e sus arravales pueda prendar y prende en la dicha dehesa e no estando el arrendador presente, e quel dicho vezino de la dicha Villa que ansí prendare en la dicha dehesa, se entregue la prenda que así prendare en la dicha dehesa al arrendador, e que el dicho arrendador de al que así llevare la dicha prenda la mitad de la pena.

Otrosí, por quanto dixeron en las tierras e viñas que están juntas e alindan con la dicha dehesa se pueden hacer muchos daños e entran muchas vestias de las que anduvieren en la dicha dehesa en los panes e viñas, e si de las tales vacas e toros se oviesen de llevar caloñas, de la manera que se llevarédes otras viñas e panes, sería en gran daño e perjuizio de los vezinos e moradores de la dicha Villa que allí truxeren sus (ganados), e por evitar ésto, ordenaron e mandaron que, de aquí adelante, no se lleven caloñas de las dichas bestias que así paçieren en la dicha dehesa, salbo solamente se pague el daño que así fuere apreçiado, segund costunbre de los apreçiar de esta dicha Villa por los panes e viñas sean obligados de dar cuenta de estos dichos daños, e por ventura no 
oviere guardas, quel arrendador que la dicha dehesa aya de dar e descuente de los dichos daños e los pague.

Estas dichas ordenanzas así fechas, se pueden acresçentar e menguar e enmendar, cada e quando viere el dicho regimiento que cunple el bien de la dicha dehesa, con tanto que para sienpre jamás no se pueda dar liçençia para que en la dicha dehesa anden yeguas ni los otros ganados defendidos. 